Revista Eletrônica de Ciência Administrativa (RECADM) - ISSN 1677-7387 Faculdade Cenecista de Campo Largo - Coordenação do Curso de Administração v. 3, n. 2, nov./2004 - http://revistas.facecla.com.br/index.php/recadm/

\title{
GESTIÓN FINANCIERA Y LEGITIMIDAD MUNICIPAL
}

Edmundo Hernández Claro Mtro. En administración Pública Universidad de Guadalajara ehernand@cucea.udg.mx

\section{RESUMEN}

A partir de los abusos que las autoridades municipales han hecho de los recursos públicos a su disposición, especialmente en el rubro de remuneraciones y compensaciones, el artículo sugiere que los gobiernos municipales enfrentan um deterioro en sus niveles de legitimidad. Destacando que el caso afecta en mayor medida a los municipios metropolitanos. Se sugiere trabajar tanto en mejores medidas de fiscalización, como en los ajustes institucionales que requieren las grandes concentraciones urbanas.

Palavras chave: Eficacia, eficiencia, gasto público, gestión, inversión municipal, legitimidad, impuesto predial, nómina, recaudación, remuneraciones, sistemas complejos

\section{ABSTRACT}

Since of the excess by the municipal authorities about the use of public resources, in reference to the remunerations, the article suggest that municipal government are facing a crisis in its levels of legitimacy. I suggest work in the improvement of the actions of supervision, and instutional adjusts, mainly for big urban concentrations.

Key words: Efficiency, efficacy, complex system, public expenditure, management, municipal investment, legitimacy, payroll, tax

Hasta hace poco tiempo era impensable que instituciones con un alto prestigio social como el municipio, vieran erosionada tan rápidamente su legitimidad como consecuencia de los abusos que han hecho de los recursos públicos a su disposición. La otrora figura mítica del municipio considerado como el espacio primario de la democracia y reserva de la moral pública, ha entrado a un proceso acelerado de rendimientos decrecientes al menos en lo que respecta a su prestigio y reconocimiento social. 
Revista Eletrônica de Ciência Administrativa (RECADM) - ISSN 1677-7387 Faculdade Cenecista de Campo Largo - Coordenação do Curso de Administração

v. 3, n. 2, nov./2004 - http://revistas.facecla.com.br/index.php/recadm/

El municipio Mexicano que siempre se había destacado por convocar a un amplio consenso en torno a la demanda de una mayor descentralización de competencias y recursos públicos de los poderes centrales hacia los gobiernos locales, recientemente se ha convertido en el blanco de un fuerte tema de controversia en virtud del uso discrecional que en muchos casos se ha hecho de la nómina de los altos servidores municipales. Para combatir tales excesos, se han sugerido nuevas iniciativas de ley y ajustes en los mecanismos y órganos de fiscalización a fin de poner un freno a tales abusos.

Esta situación, si bien de manera inmediata tiene un impacto directo sobre el control de la gestión del gobierno municipal, en términos más amplios es una invitación a discutir el sentido político y administrativo de tales desajustes. A partir de estos elementos, me propongo apuntar en estas notas algunas interpretaciones generales de la relación problemática que guardan la gestión y la legitimidad, para dar paso enseguida, a una revisión de los grandes rubros de la gestión financiera municipal, particularmente haré mención de la recaudación de los ingresos propios, del gasto de inversión y el gasto en nómina de los altos servidores municipales. Sobre estos rubros, quiero destacar algunos aspectos de la experiencia reciente del Estado de Jalisco, y sugerir finalmente algunas reflexiones sobre la agenda de discusión en torno a la reforma municipal.

Gestión y legitimidad

La gestión pública puede ser visualizada a partir de tres ejes troncales: eficiencia, eficacia y legitimidad, todos ellos enlazados en un equilibrio estratégico. Mientras que la naturaleza de la eficiencia y la eficacia son de fácil medición, la legitimidad al tener que ver con la aceptación, el apoyo y la credibilidad que un gobierno logra 
Revista Eletrônica de Ciência Administrativa (RECADM) - ISSN 1677-7387 Faculdade Cenecista de Campo Largo - Coordenação do Curso de Administração

v. 3, n. 2, nov./2004 - http://revistas.facecla.com.br/index.php/recadm/

en el desempeño de sus tareas ${ }^{1}$, se torna más compleja su evaluación en virtud de estar referida principalmente a variables de tipo cualitativo.

Algunas acciones municipales dirigidas a consolidar expresamente la legitimidad, tienen que ver con la construcción de gobiernos más democráticos, esto es, sistemas abiertos a la participación ciudadana en la toma de decisiones del ayuntamiento, así como otros programas de gobierno dirigidos a diversos grupos y sectores del municipio ${ }^{2}$.

Sin embargo, la legitimidad también tiene que ver con el déficit de gestión y en general, con los abusos del poder del que suelen hacer los ayuntamientos. Lo cual finalmente puede inclinar la balanza de la legitimidad del lado de las malas noticias de la gestión, sobre todo por lo que se haga o deje de hacer con los recursos públicos. Sobre este punto hay que tener presente, que al margen del carácter publicitario y partidario que suele hacerse de tales excesos y vacíos, está en juego la credibilidad en el gobierno municipal. Se ha puesto en tela de duda el prestigio de que había gozado como instancia de gobierno que puede resolver con mayor eficacia la detección de nuevas necesidades, la construcción del equipamiento colectivo y adoptar con mayor rapidez las decisiones que afectan a sus respectivas comunidades.

Se puede ensayar una línea general de interpretación de este problema. Y tiene que ver con el rostro del nuevo municipio que ha resultado después de la

\footnotetext{
1 - Cabrero Mendoza, Enrique y Nava Campos Gabriela (coordinadores), Gerencia Pública Municipal, conceptos básicos y estudios de caso, editoriales Miguel Àngel Porrúa y CIDE, 1999.

${ }^{2}$ Ver los programas que han participado en el Premio de Gobierno y Gestión Local, México D F, referidos a los Presupuestos participativos, formación de unidades en los ayuntamientos dedicadas a la defensa y promoción de la mujer, jóvenes y niños, y el impulso a los sistemas de gobierno abiertos a la participación ciudadana en la toma de decisiones. - GOBIERNOS LOCALES TRABAJANDO, un recorrido a través de los programas municipales que funcionan, Premio Gobierno y Gestión Local, ediciones 2001 y 2002, CIDE, Fundación Ford, Instituto Nacional para el Federalismo y el Desarrollo Municipal, y Comisión de Fortalecimiento del Federalismo, Cámara de Diputados.
} 
implementación de las reformas municipales de 1983 y 1999, así como de la transferencia de los nuevos recursos financieros que se han derivado de las políticas federales de descentralización. Con tales medidas, hoy tenemos un municipio con mayores poderes y capacidad de acción. Un municipio más autónomo, que tiene por ley, el rango de orden de gobierno. Sin embargo, lo sombrío de la cuestión, es que la mayor autonomía y fortaleza municipal, no se ha hecho acompañar de los mecanismos institucionales que garanticen una mejor gestión de los recursos a su disposición.

Asistimos entonces, a una especie de crisis de crecimiento municipal, o también a un problema de adolescencia que se traduce en la inmadurez de su autonomía; de tal manera que las imperfecciones en la organización y gestión municipal, obedecen a que la autonomía no se complementó con las responsabilidades inherentes al ejercicio de toda autoridad. Esto es, sin los contrapesos institucionales a toda forma democrática de gobierno.

¿Ante quién es responsable el aparato de gobierno municipal, por sus decisiones en el manejo del gasto municipal? Tengamos presente, que si hay un punto sobre el cual los partidos políticos representados en el gobierno municipal han logrado un pleno acuerdo, es en el de sus remuneraciones, bonos, compensaciones y otras prestaciones que consideran merecer por el desempeño de sus respectivas encomiendas.

La legitimidad municipal también puede ser analizada desde el ángulo de los Sistemas Complejos ${ }^{3}$. Con esta perspectiva, los abusos podrían interpretarse como una propiedad emergente del sistema, esto es, como una propiedad del todo y no sólo de las partes, lo que traducido al ámbito del gobierno municipal podría

\footnotetext{
3. Waissbluth Mario, La Insularidad en la Gestión Pública Latinoamericana, Revista del Centro Latinoamericano de Administración para el Desarrollo CLAD, Reforma y Democracia, No. 27, Octubre del 2003, Caracas, Venezuela.
} 
v. 3, n. 2, nov./2004 - http://revistas.facecla.com.br/index.php/recadm/

ser interpretado como una tendencia a la alineación u homologación en los formatos de gobierno y administración de los tres ámbitos de gobierno. Esto es, si bien se reconoce que existe un problema de excesos en el ámbito municipal, finalmente las soluciones que se están ensayando, apuntan hacia el mismo orden de ideas que se manejan en el plano federal, mejores sistemas de fiscalización de los recursos públicos.

Con esta perspectiva, es de esperarse un nuevo esquema organización que tal vez con medidas pertinentes de fiscalización de los recursos públicos, aspire a lograr un sistema de gobierno local más eficaz y eficiente en el manejo de sus finanzas.

En todo caso, bien se trate de un problema inmadurez institucional, o de una tendencia a la homologación de las formas de gobierno y administración, el tema requiere de un análisis y discusión más amplia. Para abonar en tal dirección, me permito apuntar enseguida, algunos datos sobre los conflictos que van asociados al manejo de las finanzas municipales, para luego retomar el caso de Jalisco.

Conflictos por la gestión de los recursos

En materia de recaudación de sus ingresos, las administraciones municipales han actuado de manera muy conservadora. Se estima por ejemplo, que a nivel nacional al menos dejan de recaudar el 1.5\% de PIB. Prácticamente en cualquier gráfica municipal que represente el comportamiento de la recaudación de sus 
v. 3, n. 2, nov./2004 - http://revistas.facecla.com.br/index.php/recadm/

ingresos, se apreciará un comportamiento moderado y a veces inestable de los ingresos propios, a diferencia de las participaciones, cuyo crecimiento casi siempre se mantiene constante.

Si tomemos por ejemplo, la recaudación del impuesto predial, observaremos que en algunos la cifra puede ir en ascenso de un período a otro, no obstante, si revisamos la cantidad recaudada respecto al padrón de contribuyentes registrados, el resultado puede estar muy por debajo de la media nacional. Cito el caso del municipio de Tepic, Nayarit, que durante el período 1999 - 2001, el padrón de contribuyentes pasó de 62,421 a 86,257 cuentas; en cambio, la recaudación del impuesto predial pasó de 26.4 millones de pesos que se recaudaron en 1999, a sólo 14.0 en el año 2001 . Aún cuando se trate del municipio capital de la entidad federativa la recaudación per cápita del impuesto predial durante el año 2001, es inferior a la de muchos municipios de menor desarrollo en el mismo estado.

Ejemplos de este tipo se puede multiplicar, pero finalmente lo relevante para el presente trabajo, es destacar que los defectos en materia de ingresos no generan necesariamente un tema amplio de discusión, salvo en los círculos financieros especializados y órganos de fiscalización, quienes pueden hacer recomendaciones para una mejor gestión.

Por otro lado, cuando nos referimos a los gastos de inversión municipal, nos encontramos frente a un panorama diferente. En este apartado cobra vigencia el discurso municipalista, con el que se argumenta que una misma inversión que es realizada por el gobierno local, resulta menos costosa que si la misma fuera ejecutada por el gobierno central. Dado que la cercanía que guarda el gobierno municipal con su comunidad, lo suele hacer más sensible a los requerimientos de sus respectivos contextos. Sin embargo, es frecuente observar que los buenos

\footnotetext{
4 "Las finanzas públicas municipales de Nayarit: evaluación de su desempeño" 2001, H Congreso del Estado de Nayarit, Órgano de Fiscalización Superior del Estado.
} 
deseos no siempre se corresponden con los hechos. Ya que es recurrente observar el desarrollo de obras y servicios que resultan incongruentes con la agenda de prioridades de tales municipios. O bien, casos de implementación de proyectos en los que su costo se duplica respecto a lo presupuestado.

Muchas de tales obras municipales, no motivan sanciones o medidas punitivas, ni tampoco generan acciones más estrictas de fiscalización sobre los gastos de inversión. En el mejor de los casos tales construcciones innecesarias o mal calculadas, se convierten en una fuente de argumentación y descalificación en las contiendas electorales; o bien pasan a formar parte del folklore y de la literatura regional ${ }^{5}$. El tema en si mismo, no suele generar un amplio impacto social, aunque suele ser más visible ante la opinión pública, que otras disfunciones de orden financiero, como sucede en el caso de la recaudación de los tributos locales.

Finalmente, cuando se trata de excesos en los gastos de nómina de los altos servidores municipales, la cuestión se convierte en un punto en disputa de amplia visibilidad y de gran impacto social. El tema de los excesos en los gastos parece entonces convocar a una discusión más amplia, que los casos de la baja recaudación en los ingresos locales. Es un asunto que genera un hondo malestar entre la población. Produce un sentimiento de desencanto, sobre todo después de las grandes expectativas que se generaron con la alternancia en el poder, en todos los ámbitos de gobierno.

Cuando se trata de los abusos en materia de remuneraciones, bonos de fin de la administración, gastos de viaje al extranjero y otras prestaciones de los altos funcionarios municipales, se genera una ola de inconformidad y cuestionamiento

\footnotetext{
${ }^{5}$ El Alcalde de Lagos, de Alfonso de Alba, editorial hexágono, es uno de los libros que retratan de manera literaria, diversos aspectos pintorescos asociados a la edificación de obras municipales.
} 
social a las autoridades locales y se erosionan los niveles de legitimidad de los gobiernos locales.

En el siguiente cuadro se resumen las relaciones comentadas entre los rubros de la gestión financiera municipal y su impacto en el grado de legitimidad:

\section{CONFLICTO Y LEGITIMIDAD \\ EN LA GESTIÓN FINANCIERA MUNICIPAL}

\begin{tabular}{||c|c|c||}
\hline $\begin{array}{c}\text { RUBROS DE LA } \\
\text { GESTIÓN } \\
\text { FINANCIERA }\end{array}$ & $\begin{array}{c}\text { NIVEL DE } \\
\text { CONFLICTO } \\
\text { SOCIAL QUE } \\
\text { GENERA }\end{array}$ & $\begin{array}{c}\text { IMPACTO EN EL } \\
\text { GRADO DE } \\
\text { LEGITIMIDAD } \\
\text { DEL GOBIERNO } \\
\text { MUNICIPAL }\end{array}$ \\
\hline $\begin{array}{l}\text { BAJA RECAUDACIÓN } \\
\text { DE } \\
\text { INGRESOS PROPIOS }\end{array}$ & BAJO & BAJO \\
\hline $\begin{array}{l}\text { GASTO DE } \\
\text { INVERSIÓN }\end{array}$ & MEDIO & MEDIO \\
\hline $\begin{array}{l}\text { EXCESOS EN LA } \\
\text { NÓMINA }\end{array}$ & ALTO & ALTO \\
\hline
\end{tabular}

A partir de tal escenario se puede señalar entonces, que la línea de legitimidad municipal, que siempre se había mantenido en ascenso, observa en este momento un quiebre o punto de inflexión, pero a la baja. Ya que todos los grupos y actores locales (con excepción claro, de los representantes municipales) coinciden precisamente en censurar tales conductas y buscar los mecanismos correctivos.

En tal sentido, la autonomía municipal resulta tan sólo una condición necesaria pero no suficiente para contar con un gobierno eficiente, eficaz y legítimo. Tales excesos, empujan por lo tanto a encontrar los contrapesos que eviten la tendencia hacia el autoritarismo por las autoridades locales.

El caso de Jalisco 
Si bien los casos de excesos en las nóminas, abarcan a todos los ámbitos de la administración pública, en el caso de los gobiernos municipales, esto ha cobrado una gran controversia en los medios de comunicación, que se han traducido en diversas iniciativas de gobierno. En el estado de Jalisco ${ }^{6}$, se han emprendido las siguientes acciones para corregir estos desajustes:

- Una primera acción que se implementó, fue la creación del Comité Técnico de Valoración Salarial CTVS, constituido en 2001 para revisar un amplio espectro de puestos correspondientes a los tres poderes del Gobierno del Estado de Jalisco y el de sus municipios. Para 124 municipios en que se dividía el Estado, se formaron nueve estratos, evaluándose por cada uno, al presidente municipal y al regidor, y recomendándose en consecuencia nuevos rangos de remuneración.

- A partir del presente año se cuenta también en Jalisco con una La Ley de Fiscalización Superior, la que otorga facultades a la Auditoría Superior, pero sólo a partir de los ejercicios del año 2004 ,

- El Ejecutivo del Estado por su parte, propuso en una Iniciativa turnada al Congreso Local el 17 de febrero de 2004, propuso reformar el artículo 111 de la Constitución Política Local, que señala que las remuneraciones deberán ser "justa, equitativa e irrenunciable" la iniciativa incluye nuevos criterios "cumplir con los principios de austeridad, disciplina presupuestal, racionalidad, proporcionalidad, certeza y motivación".

- En otra iniciativa de un legislador del Partido Revolucionario Institucional PRI, se propuso crear la Ley de Valoración Salarial, con la que se busca definir los topes

\footnotetext{
6 Basta señalar que la legislatura del Estado (2001 - 2004), fincó sanciones económicas en 84 administraciones municipales durante el período 1998 a 2002. Ex presidentes municipales y ex tesoreros fueron sancionados con 30 millones, 72,415 pesos, pero a la fecha han reintegrado a las arcas municipales sólo 2 millones, 477,690 pesos. El poder legislativo no puede obligar a los funcionarios municipales a pagar.
} 
máximos y mínimos en los sueldos de los funcionarios públicos. Además de proponer la desaparición del CTVS.

- El Partido de la Revolución Democrática PRD, a través de un Legislador local propuso, Ciudadanizar el Comité Técnico de Valoración Salarial (CTVS). Elevarlo a rango constitucional, otorgándole autonomía y facultades de dictaminación y sanción, además facultarlo para que rija las relaciones de trabajo entre el estado, los municipios y entidades paraestatales.

- Una iniciativa más del Ayuntamiento de Guadalajara, fue la creación del Consejo Municipal para la Transparencia y el Combate a la Corrupción, el que se ha avocado a investigar si los exregidores, recibieron bonos de fin de trienio.

Todas estas iniciativas quizás dispersas, aspiran en última instancia a poner en práctica mecanismos de corrección que de alguna forma han sido ensayadas por los gobiernos centrales. Proponen en términos generales, más y mejor fiscalización, instancias ciudadanas que garanticen la transparencia en el manejo de los recursos, y medidas punitivas que dificulten al máximo la comisión de abusos contra la nómina.

Un problema adicional y de mayor alcance que está inmerso en esta problemática, es la cuestión de la legitimidad de una institución histórica y de alto reconocimiento social como es el municipio. Se trata de una infección que se puede tratar con una dosis de fiscalización, o bien, estamos frente a un síntoma de una enfermedad más grave, que podríamos llamar alineamiento o pérdida de identidad institucional, y cuyo tratamiento demanda un nuevo enfoque clínico. 


\section{Comentarios finales}

En un plano inmediato, es necesario abatir la enfermedad, con mejores modelos de fiscalización, con medidas correctivas que pongan orden a los desfalcos que se han cometido contra el patrimonio público. Pero adicionalmente se requiere discutir con una visión de Estado, la necesidad de reconfigurar el sistema de gobierno y administración municipal, a la luz de un escenario más complejo frente al cual, el formato del municipio tradicional se ha quedado a la zaga. Requerimos una agenda de discusión más fresca, que deje de lado las coyunturas e intereses de los partidos y facciones políticas, para dar paso a una auténtica discusión sobre los ajustes instuitucionales que requiere el municipio.

\section{Bibliografia}

CABRERO Mendoza Enrique y Nava Campos Gabriela, (coordinadores), Gerencia Pública Municipal, conceptos básicos y estudios de caso, editoriales Miguel Ángel Porrúa y CIDE, 1999.

DE ALBA Alfonso, El Alcalde de Lagos, editorial Hexágono 1992.

GOBIERNOS locales trabajando un recorrido a través de los programas Municipales que funcionan, Premio Gobierno y Gestión Local, 2001 y 2002, CIDE y Fundación Ford.

LAS FINANZAS públicas de Nayarit: evaluación de su desempeño, 2001, H Congreso del Estado de Nayarit, Órgano de Fiscalización Superior del Estado.

WAISBLUTH Mario, La insularidad en la gestión pública Lationoamericana, Revista del Centro Latinoamericano de Administración para el Desarrollo, CLAD, Reforma y Democracia No. 27, octubre del 2003, Caracas, Venezuela. 